\title{
A EDUCAÇÃO PERMANENTE E AS PRÁTICAS EM SAÚDE: CONCEPÇÕES DE UMA EQUIPE MULTIPROFISSIONAL
}

\author{
PERMANENT EDUCATION AND THE HEALTH PRACTICES: \\ PERCEPTIONS OF THE MULTIPROFESSIONAL-TEAM
}

\author{
Márcia Parente Silva Lamante ${ }^{1}$ \\ Mara Quaglio Chirelli ${ }^{2}$ \\ Danielle Abdel Massih Pio ${ }^{3}$ \\ Silvia Franco da Rocha Tonhom ${ }^{4}$ \\ Maria Cristina Martinez Capel $^{5}$ \\ Maria Elizabeth da Silva Hernandes Corrêa ${ }^{6}$
}

Resumo: A Educação Permanente em Saúde (EPS) reconhece que é possível por meio de um processo reflexivo, o cuidado integral e humanizado. O objetivo deste estudo foi analisar como uma estratégia de EPS mobilizou a prática da equipe multiprofissional em uma unidade hospitalar. Estudo qualitativo, composto por três etapas: dois grupos focais, realizados de forma prévia e posterior à intervenção subsidiada pelo Planejamento Estratégico Situacional. Utilizou-se como referencial metodológico, o Discurso do Sujeito Coletivo. Nos resultados verificou-se ganho de conhecimentos, novas habilidades e atitudes exploradas a partir da subjetividade dos encontros. Mudanças aconteceram com relação à identificação da potencialidade da EPS, seus alcances e efetividade como ferramenta de gestão e de construção de uma práxis. A organização desta proposta pode ser motivadora para a realização de EPS em outros espaços, por permitir a grupalidade e a cogestão de processos de trabalho.

Palavras-chave: Educação Permanente em Saúde; Integralidade em saúde; Capacitação em Serviço; Planejamento em Saúde.

\begin{abstract}
The Permanent Education in Health (PEH) recognizes that it is possible through a reflexive process, the integral and humanized care. The objective of this study was to analyze how a strategy of PEH mobilized the practice of the multiprofessional team in a hospital unit. Qualitative study, composed of three stages: two focus groups, carried out before and after the intervention subsidized by the Strategic Situational Planning. The Collective Subject Discourse was used as methodological reference. In the results it was verified gain of knowledge, new abilities and attitudes explored from the subjectivity of the meetings. Changes occurred in relation to the identification of the potentiality of EPS, its scope and effectiveness as
\end{abstract}

\footnotetext{
${ }^{1}$ Mestre em Ensino e Saúde pela Faculdade de Medicicna de Marília (FAMEMA). Faculdade de Medicina de Marília (FAMEMA), Marília, São Paulo, Brasil. E-mail: marcialamante@uol.com.br

${ }^{2}$ Doutora em Enfermagem pela Escola de Enfermagem de Ribeirão Preto - USP (EERP-USP). Faculdade de Medicina de Marília (FAMEMA), Marília, São Paulo, Brasil. E-mail: marachirelli@ gmail.com

3 Doutora em Saúde Coletiva pela Universidade Estadual Paulista - Botucatu (UNESP-Botucatu). Faculdade Medicina de Marília (FAMEMA). Marília, São Paulo, Brasil. E-mail: danimassihpio@hotmail.com

${ }^{4}$ Doutora em Educação pela Universidade de Campinas (UNICAMP). Faculdade de Medicina de Marília (FAMEMA), Marília, São Paulo, Brasil. E-mail: siltonhom@gmail.com

${ }^{5}$ Doutora em Enfermagem Fundamental pela Escola de Enfermagem de Ribeirão Preto - USP (EERPUSP). Faculdade de Medicina de Marília (FAMEMA), Marília, São Paulo, Brasil. E-mail: cricapel@gmail.com

${ }^{6}$ Doutora em Saúde Pública pela Universidade de São Paulo (USP). Universidade de Marília (UNIMAR), Marília, São Paulo, Brasil. E-mail: meshco@gmail.com
} 
a tool for management and construction of a praxis. The organization of this proposal can be motivating for the execution of EPS in other spaces, because it allows grouping and co-management of work processes.

Keywords: Permanent Education in Health; Integrality in health; Training in Service; Health Planning.

\section{Introdução}

Com a crescente tendência à busca de métodos inovadores, que admitam uma prática pedagógica ética, crítica, reflexiva e transformadora (MITRE et al., 2008) tornase necessário que cada vez mais ocorram mudanças nas metodologias de ensino.

Segundo Ceccim e Feuerwerker (2004, p.43):

A formação não pode tomar como referência apenas a busca eficiente de evidências ao diagnóstico, cuidado, tratamento, prognóstico, etiologia e profilaxia das doenças e agravos. Deve buscar desenvolver condições de atendimento às necessidades de saúde das pessoas e das populações, da gestão setorial e do controle social em saúde, redimensionando o desenvolvimento da autonomia das pessoas até a condição de influência na formulação de políticas do cuidado.

Nessa perspectiva, a gestão necessita proporcionar possibilidades de transformação das práticas por meio da reflexão crítica sobre o trabalho em saúde. A formação deve abordar aspectos de produção subjetiva, habilidade técnica e conhecimento do Sistema Único de Saúde (SUS) (CECCIM; FEURWERKER, 2004).

A partir da década de 70, a Organização Pan Americana de Saúde (OPAS) inicia discussões acerca da necessidade de transformação da prática dos profissionais de saúde, visto que as equipes não atendiam às demandas dos serviços (LOPES et al., 2007).

Passa-se a exigir novas posturas, com o deslocamento do conceito de qualificação para o de competência. Significa que os profissionais deverão saber tomar decisões em processo e em equipe. No entanto, temos vivido a soberania da concepção de educação liberal, a qual tem como finalidade a adequação da força de trabalho a um modelo de competitividade que atende ao mercado e às empresas (DELUIZ, 2010).

A abordagem dialógica de competência vem ampliar os caminhos da educação e do trabalho, ao possibilitar a formação de um profissional a partir da reflexão sobre sua prática, com a mobilização de habilidade cognitiva, psicomotora e atitudinal nas diferentes situações, incorporando seus valores pessoais à ética como elementos do desempenho na tomada de decisão (LIMA; PADILHA, 2018).

É importante que a construção de práticas de saúde ampliadas e compartilhadas seja fortalecida pela capacidade dos profissionais de analisar, intervir e refletir sobre os 
efeitos de sua prática, sobre o que se passa na relação entre esses profissionais da equipe e entre a equipe e os usuários (CAMPOS; CUNHA; FIGUEIREDO, 2013).

Nessa perspectiva, a estrutura do Ministério da Saúde foi reformulada em 2003, ano marcado por uma mudança administrativa no governo federal. Foi criada pelo decreto 4.726, de 9 de junho do mesmo ano, a Secretaria de Gestão do Trabalho e da Educação na Saúde (SGTES), e nela o Departamento de Gestão da Educação na Saúde (DEGES) (TORRES, 2013).

As ações de Educação Permanente em Saúde (EPS) tornam-se estratégicas na medida em que constituem a SGTES e o DEGES, com avanços até a portaria 198/GM/MS em 13/02/2004 que instituiu a Política Nacional de Educação Permanente (PNEP) (LOPES et al., 2007). Havia uma intenção de se propor a EPS como uma política para que, por meio da reflexão sobre a prática profissional, ocorresse a transformação da lógica organizacional e das próprias práticas constituídas.

A EPS vem, portanto, como estratégia para transformação da prática e tem como principal desafio, estimular o desenvolvimento da consciência nos profissionais sobre seu contexto, sobre sua responsabilidade pelo próprio processo permanente de mudança com a constituição de sujeitos (MERHY, 2000). A EPS se torna um caminho para que o trabalho venha a ser lugar de atuação crítica, reflexiva, compromissada e tecnicamente competente.

No Brasil, a EPS apresenta outros contornos. Dentre os quais, amplia a integração ensino-serviço para a ideia de quadrilátero da formação, buscando-se romper o planejamento centralizado, deslocando as discussões das mudanças para espaços coletivos com o envolvimento de trabalhadores, gestores, usuários (controle social), professores/acadêmicos (LEMOS, 2016).

No entanto, como toda política pública, a PNEP teve suas dificuldades. Batista e Gonçalves (2011, p.886) nos dizem que:

\begin{abstract}
Apesar de alguns avanços, a formação dos profissionais de saúde ainda está muito distante do cuidado integral. O perfil dos profissionais de saúde demonstra qualificação insuficiente para as mudanças das práticas. Uma necessidade crescente de educação permanente para esses profissionais, com o objetivo de (re) significar seus perfis de atuação, para implantação e fortalecimento da atenção à saúde no SUS é um grande desafio[...].
\end{abstract}

Nessa perspectiva de organização dos serviços, é necessário que os profissionais não mais realizem seu trabalho baseados no saber das profissões e sim em objetivos comuns que garantam que as práticas dos trabalhadores se complementem, oferecendo 
aos usuários um tratamento digno e afetuoso, em que se criem vínculos e o acolhimento esteja presente.

As práticas humanizadas em saúde perdem a força de produzir mudanças nos sujeitos e no trabalho ao serem reduzidas a ações desarticuladas que não colocam em análise os processos (SANTOS FILHO; BARROS; GOMES, 2009).

O trabalho é considerado por Merhy e Franco (2003) como um espaço de encontro entre sujeitos trabalhadores e usuários. É, portanto, onde se dá o cuidado em saúde e somente nele conseguimos operar satisfatoriamente a integralidade.

Para que se possa trabalhar nessa perspectiva, as metodologias ativas são mais apropriadas à EPS, por serem novas formas de ensino-aprendizagem, potencializando a integração teoria e prática, ensino e serviço, e também as diferentes profissões da área da saúde. Elas promovem a capacidade de reflexão sobre a realidade vivida e o desenvolvimento de ações para que essa realidade seja transformada (HOFFMANN; KOIFMAN, 2013).

Em relação à aprendizagem significativa, identifica-se suas origens no movimento da educação progressista, que destacou a necessidade de aproximação do ensino à prática cotidiana. Quando o processo de aprender é desencadeado por um problema do cotidiano, os participantes utilizam seus saberes prévios para identificar a natureza deles e para formular perguntas que permitam buscar novos sentidos e significados para interpretar o fenômeno encontrado (AUSUBEL; NOVAK; HANESIAN, 1980).

A interpretação construtivista da intervenção pedagógica ressalta os elementos da teoria da aprendizagem significativa de Ausubel (AUSUBEL; NOVAK; HANESIAN, 1980) e a contribuição da teoria sociocultural de Vygotsky (1998), relacionando desenvolvimento, aprendizagem e ensino e sua funcionalidade como elementos do processo de construção do conhecimento.

Segundo Arruda et al., (2010), o modelo construtivista defende a aprendizagem ativa e a concepção do aprender a aprender, formando um sujeito corresponsável pela construção do conhecimento.

Assim, ao acreditar na potência da vinculação EPS e metodologias ativas, como um conjunto de estratégias e valores pelos quais se deve lutar e cujo grande desafio é envolver os profissionais para a realização de um cuidado voltado às necessidades de saúde das pessoas, com a criação do vínculo e da empatia (OLIVEIRA; CUTOLO, 2012), é que se deu a necessidade do desenvolvimento do presente estudo. 
Diante desse contexto, a questão principal a se investigar foi: a vivência em processos de EPS influencia a prática profissional na perspectiva da integralidade do cuidado? Assim, objetivou-se analisar de que modo uma estratégia de EPS mobilizou a prática da equipe multiprofissional em uma unidade hospitalar.

\section{Metodologia}

Trata-se de um estudo qualitativo, recorte de uma dissertação de mestrado, também apresentado em Lamante et al., $(2018)^{7}$, composto por três etapas: dois grupos focais, realizados de forma prévia e posterior a uma intervenção com atividade de EPS subsidiada pelo Planejamento Estratégico Situacional (PES) (MATUS, 1993). Como referencial metodológico de análise, foi utilizado o Discurso do Sujeito Coletivo (DSC) (LEFÈVRE; LEFÈVRE, 2003).

Após os trâmites éticos, com parecer de $\mathrm{n}^{\circ}$ 1.363.066, foi realizado o primeiro grupo focal (TRAD, 2009) com a participação de nove pessoas da equipe multiprofissional de uma unidade de internação em um hospital de ensino no interior paulista. A amostra intencional foi composta por uma médica, duas enfermeiras, uma assistente social, uma psicóloga, uma fisioterapeuta e três auxiliares de enfermagem que já trabalhavam na unidade, além da facilitadora e da moderadora.

Esse primeiro grupo focal (primeira etapa) procurou captar como os profissionais realizavam suas práticas antes da implementação da EPS, por meio de um roteiro com questões abertas e disparadoras sobre o cuidado realizado, integralidade, trabalho em equipe e educação permanente, com o objetivo de obter informações sobre o conhecimento da equipe acerca dos temas. Essa etapa foi em um encontro com duração de uma hora e dez minutos.

O grupo focal consiste em uma técnica de pesquisa qualitativa, derivada de entrevistas grupais em um ambiente de interação para obter-se dados da pesquisa. Tem como objetivo, apreender percepções, valorizar e perceber dimensões subjetivas frente a um determinado tema, valorizando as diferentes visões sobre o assunto. Possui um roteiro estruturado, inicialmente com questões mais fáceis de serem respondidas, incentivando a participação de todos e, posteriormente, com questões mais específicas (TRAD, 2009).

\footnotetext{
${ }^{7}$ Este manuscrito é versão aprofundada do artigo citado, publicado em Atas CIAIQ2018.
} 
O número de participantes deve ser entre 6 a 15 pessoas, sendo que esta determinação influenciará a sua duração, que deve variar de 90 a 110 min. Deve ser coordenado por um moderador, que tenha conhecimento sobre o tema e habilidades para o trabalho em grupo, podendo ser apoiado por um segundo moderador e acompanhado por um observador externo, que não se manifesta, tendo como função captar a reação dos participantes (TRAD, 2009).

Após a primeira etapa, foi realizada a intervenção (segunda etapa) com a mesma equipe, problematizando o processo de trabalho que qualificasse o cuidado ao usuário. $\mathrm{O}$ método escolhido para desenvolvimento da problematização e das atividades nos encontros de EPS, foi o PES (MATUS, 1993).

Segundo Matus (1993), o PES explica uma realidade social, envolvendo atores sociais, responsáveis pelas mudanças situacionais. Permite trabalhar os problemas e processos sociais e promove a construção de planos de ação para enfrentamento dos problemas nas instituições (MARQUES, 2011).

O PES (MATUS, 1993) é um planejamento democrático, em que diversos atores compartilham poder e pode ser aplicado em diversas situações onde há conflito de qualquer natureza.

A intervenção ocorreu quinzenalmente. Houve um total de 13 encontros, com duração de 90 minutos cada um, em sala específica situada na unidade hospitalar, em dias e horários combinados com os participantes e mediante escala estabelecida com a diretoria do hospital. A atividade foi conduzida por facilitador capacitado em EPS, não havendo a participação da pesquisadora.

Toda a coleta de dados não foi realizada pela pesquisadora, considerando que essa exercia cargo de gestão na instituição pesquisada e isso poderia ter interferência durante os procedimentos.

Após o desenvolvimento dos encontros de EPS em sete meses, foi realizado novo grupo focal (terceira etapa) com o grupo de profissionais que participaram da primeira etapa e após participarem da segunda etapa, a intervenção. Nesta etapa participaram sete integrantes, duas enfermeiras, uma psicóloga, uma assistente social, uma fisioterapeuta e duas auxiliares de enfermagem. Tinha-se como intenção captar se a estratégia de intervenção por meio de EPS teve potencial para mobilizar os participantes e sinalizar possibilidades de mudanças em suas práticas. 
Foi utilizado um roteiro, com questões abertas, disparadoras sobre como tinha sido realizado o processo de educação permanente, como está sendo executada a prática do cuidado, considerando as atividades dos encontros de EPS, e sua avaliação.

Após a coleta de dados da primeira fase, iniciou-se a análise dos dados por meio do DSC. Trata-se de uma proposta de organização e tabulação de dados qualitativos de natureza verbal, obtidos de depoimentos. Tendo como fundamento a teoria da Representação Social, a proposta consiste basicamente em analisar o material verbal coletado e extraído de cada um dos depoimentos. O DSC tem os depoimentos como matéria prima, sob a forma de um ou vários discursos-síntese escritos na primeira pessoa do singular. Esse expediente visa expressar o pensamento de uma coletividade, como se esta coletividade fosse o emissor de um discurso (LEFEVRE; CRESTANA; CORNETTA, 2003).

A técnica consiste basicamente em analisar o material verbal coletado em pesquisas que tem depoimentos como sua matéria prima, extraindo-se de cada um destes depoimentos as Ideias Centrais ou Ancoragens e as suas correspondentes Expressões Chave; com as Ideias Centrais/Ancoragens e Expressões Chave semelhantes compõe-se um ou vários discursos-síntese que são os Discursos do Sujeito Coletivo (LEFÈVRE; LEFÈVRE, 2003, p. 18).

Para contemplar o propósito deste estudo, será realizado um recorte das ideias centrais que traduziram a análise do percurso da EPS, organizadas em processo de EPS, prática do cuidado e avaliação do processo de EPS.

\section{Resultados}

A análise das respostas obtidas sobre o processo de EPS, a prática do cuidado considerando as atividades da EPS e a sua avaliação está estruturada nas tabelas 1, 2 e 3, que apresentam as ideias centrais acompanhadas de seus respectivos discursos,

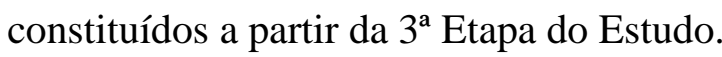

Quadro 1: Ideias centrais e Discurso do Sujeito Coletivo sobre o Processo de EPS, $3^{\mathrm{a}}$ Etapa do Estudo, 2019

\begin{tabular}{|c|c|}
\hline $\begin{array}{l}\text { Processo de EPS - Comente cor } \\
\text { momentos. Como você analisa e }\end{array}$ & $\begin{array}{l}\text { o foi realizado o processo de EPS com a equipe. Dê exemplos desses } \\
\text { te processo de EPS? }\end{array}$ \\
\hline $\begin{array}{l}\text { IC1: EPS realizada como } \\
\text { processo de reflexão delineado e } \\
\text { sistematizado em etapas }\end{array}$ & $\begin{array}{l}\text { DSC1: E esse processo de educação permanente permitiu ao mesmo } \\
\text { tempo em cada etapa uma reflexão do porquê e que ajudou a pensar } \\
\text { numa coisa que a gente já tinha como problema, mas não tinha pensado } \\
\text { numa solução dessa forma tão delineada, tão sistematizada como foi a } \\
\text { educação permanente. A educação permanente permitiu aprender esse } \\
\text { processo de reflexão, esse caminhar em etapas, em processo, }\end{array}$ \\
\hline
\end{tabular}




\begin{tabular}{|c|c|}
\hline & $\begin{array}{l}\text { respeitando as ordens das coisas, os profissionais, os setores } \\
\text { responsáveis por cada um. }\end{array}$ \\
\hline $\begin{array}{l}\text { IC2: Momento essencial de } \\
\text { análise e reflexão dos processos } \\
\text { de trabalho e da prática } \\
\text { profissional. }\end{array}$ & $\begin{array}{l}\text { DSC2: É enquanto necessidade, esse momento representa um início do } \\
\text { uso dessa estratégia, ferramenta, mas avalio como um momento } \\
\text { essencial para que a gente pare e olhe como o serviço está organizado, } \\
\text { como está a nossa prática. Porque, às vezes, a gente não pensa e vai } \\
\text { refletir depois e, às vezes, as coisas já aconteceram, já tomamos } \\
\text { atitudes. Quando é uma coisa contínua, é um exercício que a gente está } \\
\text { fazendo o tempo inteiro sobre o nosso papel, sobre a nossa prática, o } \\
\text { que eu posso fazer para mudar e fazer melhor, enquanto grupo também. }\end{array}$ \\
\hline $\begin{array}{l}\text { IC 3: O espaço é necessário e } \\
\text { potente para promover } \\
\text { crescimento, com otimização do } \\
\text { tempo e qualificação do serviço }\end{array}$ & $\begin{array}{l}\text { DSC3: Desconstruir essa ideia de nós estarmos reunidos mais uma } \\
\text { hora, num espaço que não seja assistência, porque se otimiza tempo e } \\
\text { se qualifica o serviço. Se otimiza o tempo porque à medida que a gente } \\
\text { consegue resolver os problemas, quando a gente volta para a realidade, } \\
\text { a forma com que a gente atende e trabalha já é diferente [...]. A partir } \\
\text { do momento que o espaço traz os dados positivos para nossa prática, } \\
\text { ele não é mais um espaço, também para a gente refletir sobre os nossos } \\
\text { espaços, a qualidade dos espaços e qual o resultado que ele está } \\
\text { gerando na nossa prática.... [...]. }\end{array}$ \\
\hline $\begin{array}{l}\text { IC 4: Proporciona a construção e } \\
\text { a satisfação coletiva, pelo } \\
\text { compartilhamento } \\
\text { problemas no grupo er a } \\
\text { corresponsabilização } \\
\text { resultados }\end{array}$ & $\begin{array}{l}\text { DSC4: }[\ldots] \text { porque se a gente está dizendo de um trabalho que é em } \\
\text { equipe e que todo mundo acaba sendo afetado de alguma forma. A } \\
\text { gente precisa começar a pensar coletivamente porque senão tomo } \\
\text { decisões no meu espaço [...] e a gente não conversa sobre isso. Quando } \\
\text { a gente se junta, como foi rica a forma como a gente construiu } \\
\text { estratégias para resolver o problema considerando a realidade de cada } \\
\text { um que está aqui. Porque [...] cada um é afetado de uma forma, e o } \\
\text { quanto isso se compõe quando se estabelece estratégias para resolver } \\
\text { aquele problema, [...] eu avalio como essencial, uma necessidade já, } \\
\text { urgente. }\end{array}$ \\
\hline
\end{tabular}

Fonte: material da pesquisa

Quadro 2: Ideias centrais e Discurso do Sujeito Coletivo sobre a Prática do cuidado. $3^{\mathrm{a}}$ Etapa do estudo, 2019

Prática do cuidado - Como você realiza a sua prática do cuidado na equipe em que você trabalha a partir dos encontros de EPS? Houve alguma mudança? Justifique. Essas situações (de mudança) têm relação com as atividades de EPS? Justifique.

IC5: Percepção que cada um tem a DSC5: Quando alguém comenta algum problema, como esse que sua responsabilidade no processo e era um problema que a gente já tinha identificado, agora existem que a governabilidade é relativa.

condições de falar que nós estamos trabalhando nisso, nós estamos com uma proposta. Acho que você se sente empoderada. Estamos cuidando disso. Então, traz outro problema porque nesse, não que está resolvido, mas estamos pensando. Não depende só de nós, não temos a ilusão de achar que somente o acolhimento que vai se fazer ali. Os residentes vão ser diferentes? Não, mas eles precisam se aproximar disso e é parte nossa isso.

Fonte: material da pesquisa

Quadro 3: Ideias centrais e Discurso do Sujeito Coletivo sobre a Avaliação do processo de EP. $3^{\mathrm{a}}$ Etapa do estudo, 2019

Avaliação do processo de EP - O que vocês consideram que o processo possa ter trazido como potencialidade ou situações que poderiam ter sido trabalhadas de outra forma?

IC6: O fazer da EP favorece a DSC6: Uma potencialidade é essa aproximação delas com a gente valorização de todos os nesse pensar, porque elas (profissionais de nível superior) são muito 


\begin{tabular}{|l|l|}
\hline $\begin{array}{l}\text { profissionais e a horizontalidade } \\
\text { do processo }\end{array}$ & $\begin{array}{l}\text { próximas da gente ali trabalhando, mas, parecia que existia, acho que } \\
\text { isso é cultural, uma diferença: nós somos auxiliares e elas estão num } \\
\text { nível superior. [...]. Então, tentando mostrar que todo mundo tem } \\
\text { potencialidades, todo mundo tem capacidades, um ajudando o outro, } \\
\text { sendo que os problemas são nossos. Isso foi muito potente porque } \\
\text { evidenciaram nos encontros passados e embora exista uma coisa } \\
\text { cultural, que isso começa a se desconstruir, sendo que existe sempre } \\
\text { uma hierarquia no processo de trabalho que deve ser respeitada [...]. }\end{array}$ \\
\hline $\begin{array}{l}\text { IC7: A corresponsabilização de } \\
\text { todos nas ações e na resolução } \\
\text { dos problemas. }\end{array}$ & $\begin{array}{l}\text { DSC7: Vocês também são responsáveis por isso [...] traz também essa } \\
\text { responsabilidade. Agora o negócio também é nosso [...] }\end{array}$ \\
\hline
\end{tabular}

Fonte: material da pesquisa

\section{Discussão}

O trabalho foi iniciado a partir do uso de uma ferramenta do planejamento em saúde na atividade de EPS, o que resultou em acréscimos de conhecimentos, mas também no desenvolvimento de novas habilidades e atitudes exploradas a partir da subjetividade do encontro do grupo. O trabalho, então, deu-se por meio da construção da competência dialógica (LIMA; PADILHA, 2018). Esse referencial está ancorado na abordagem holística de competência, que considera que os conhecimentos, habilidades e atitudes se desenvolvem de forma integrada, em um determinado contexto e cultura local. Ou seja, a possibilidade de os participantes poderem ampliar sua capacidade de análise reflexiva ocorreu em função de um movimento singular de cada sujeito, com atitude pró-ativa para o que foi proposto e também da gestão que possibilitou que essa prática ocorresse.

O PES (MATUS, 1993), realizado durante a atividade de EPS, mostrou-se uma ferramenta potente para a reflexão sobre o processo de trabalho, promovendo o diálogo entre os participantes, o levantamento de problemas, a criação de propostas de intervenção para melhoria da prática, proporcionando o reconhecimento, por parte dos trabalhadores, de sua capacidade de mobilização e de ser sujeito em seus processos de vida e trabalho.

O que mudou significativamente foi o entendimento da construção coletiva de cada etapa, ressaltando a participação de todos no processo e no produto das ações, fato ilustrado pelo DSC 1 (quadro 1), no qual se destaca o caminhar em etapas do processo com organização e reflexão.

A proposta pode ser avaliada pela valorização posterior do espaço da micropolítica (FEUERWERKER, 2014), visto como momento essencial de transformação do fazer da prática em práxis (ONOCKO-CAMPOS, 2012). O DSC 2 
(quadro 1) traduz esse momento, ao se ter o reconhecimento de que a prática comumente não se faz de forma reflexiva. Porém, essa habilidade e a atitude reflexiva podem ser exercitadas e incorporadas na tomada de decisões no cotidiano, sendo o espaço de EPS considerado como instrumento de formação para haver essas mudanças atitudinais.

No estudo de Rossetti et al., (2019), identificou-se que os processos de EPS constituem fator motivador das práticas profissionais e, no relato da maioria dos profissionais, propiciam mudança de postura. Outros participantes, por sua vez, não reconheceram tais mudanças, apontando como causas a resistência dos profissionais ou o não acompanhamento e monitoramento do processo educativo.

Isso fortalece a ideia de que, quando a EPS não é incorporada no fazer de um determinado serviço, as práticas de cuidado e formas de pensar se mantêm individuais e engessadas e o espaço para a reflexão das práticas do trabalho em equipe, nos serviços de saúde, permanece em segundo plano ou nem acontece (STROSCHEIN; ZOCCHE, 2011).

Além disso, a EPS passa a ser valorizada como ferramenta de gestão (CECCIM; FEUERWERKER, 2004), como apresentado pelo DSC 3 (quadro 1). Ao destacarem que o espaço reflexivo não é somente mais um momento do trabalho ou de perda de tempo, percebem que essa prática se realiza para melhorar o fazer do dia a dia e, ao mesmo tempo, busca resoluções para os problemas que até já tinham sido identificados, embora não houvesse espaço e nem ferramentas para buscarem soluções coletivas. Por outro lado, ainda há uma percepção mecânica de que se discutem, elaboram-se e aplicam-se as soluções. Portanto, os processos de EPS necessitam de continuidade para que os participantes possam refletir sobre as práticas, elaborar novas estratégias, poderem viver o que foi elaborado e retomarem as discussões reflexivas e críticas de como ocorreram essas novas formas de organizar e fazer o trabalho. Mostra-se, dessa forma, um movimento contínuo em espiral de ação-reflexão-ação.

Novas posturas e melhoria na forma de cuidar devem ser incentivadas utilizandose um instrumento permanente como a EPS. Esta surge como recurso estratégico para gestão do trabalho e educação na saúde, valorizando a responsabilidade dos serviços na transformação das práticas profissionais (LEMOS, 2016).

Neste sentido, o DSC 4 (quadro 1) valoriza o fortalecimento do trabalho em equipe e a corresponsabilização, ressaltando o trabalho coletivo e reconhecendo que, de alguma forma, todos estão envolvidos e afetados pelas ações realizadas. Ou seja, as ações decididas em equipe têm repercussão em todos que atuam no local, mas também na coletividade institucional. Ao se constituírem estratégias coletivamente há possibilidade 
de trocas das formas de pensar e pactuar outras estratégias para possibilitar novas experiências.

Para além do aprimoramento técnico-científico, a EPS busca mudanças rumo à integralidade e à resolubilidade das necessidades e demandas de todos envolvidos no cuidado em saúde. Elas não devem surgir de necessidades individuais ou de gestão, mas sim a partir da problematização do próprio fazer (BARTH et al., 2014).

Barth et al., (2014) ressaltam a necessidade da construção da EPS na e para a realidade local, focalizando a aprendizagem no trabalho. Assim, a EPS consolida práticas de transformação da ação, potencializa condutas interdisciplinares, a gestão compartilhada, a integração ensino-serviço, além da integralidade e humanização da assistência.

Como processo formativo, a EPS inclui o empoderamento dos profissionais com relação à própria prática com a possibilidade de sua modificação pela construção de conhecimento e apropriação do processo, como destaca o DSC 5 (quadro 2). Nessa perspectiva, a gestão compartilhada das intervenções promove a inclusão e a responsabilização do coletivo, proporcionando valorização dos sujeitos no processo.

Rossetti et al., (2019) relatam, em experiência realizada, que a EPS precisa ser processada a partir das necessidades identificadas e das demandas do processo de trabalho dos profissionais de saúde ou, ainda, pelas deficiências percebidas pelos profissionais, tendo todos os atores envolvidos: trabalhadores, gestores e usuários do SUS num processo compartilhado.

Assim, se constroi a horizontalidade dos saberes, diminuindo a hierarquia de poderes e papéis. Como refere Onocko-Campos (2012), o espaço da construção coletiva exige lugar, tempo e um fazer, não se resolvendo situações apenas com a reflexão. Isso só pode ser pensado se for aberto o campo do planejamento a outras disciplinas e saberes, com espaço de suporte e compartilhamento como mostra o DSC 6 (quadro 3). Os participantes da pesquisa percebem que, por meio da EPS, constitui-se espaço para diálogo e que esse possibilita uma aproximação entre os níveis hierárquicos, numa tentativa de valorização das potencialidades existentes em todos.

Isso nos faz refletir e acrescentar sobre a tendência da divisão social do trabalho, que silencia vozes menos qualificadas formalmente, como salienta Onocko-Campos (2012). Como espaço heterogêneo, a EPS promove a troca de informações, permitindo o uso da palavra a pessoas muito sensíveis às modulações do cotidiano (ONOCKOCAMPOS, 2012). 
De acordo com Barth et al., (2014, p. 610): “A EPS busca romper com essas formas de aprendizagem no trabalho, ultrapassando barreiras hierárquicas, buscando a interdisciplinaridade, a constante troca de saberes e vivências entre os profissionais".

Em outro estudo, a EPS favoreceu que todos se sentissem corresponsáveis no espaço da prática e principalmente no andamento de um projeto evidenciado no DSC 7 (quadro 3): "Vocês também são responsáveis por isso [...] traz também essa responsabilidade. Agora o negócio também é nosso [...]”.

Vasconcelos et al., (2016), ao retomarem a PNEP e a Política Nacional de Humanização (PNH), valorizam e propõem o ensinar e aprender incorporados nos processos cotidianos de trabalho e nos problemas/fazeres/saberes que ali são apresentados e inventados. Assim, no cotidiano dos serviços de saúde, em seus modos de fazer atenção e gestão, é primordial a construção de processos de formação que envolvam e funcionem no cotidiano dos serviços e redes de saúde.

Para além da construção do fazer, a constituição da grupalidade permite a ênfase em um projeto singular, comum, em que a experiência pode ser transformadora dos sujeitos em questão.O trabalho realizado na EPS pode ser disparador e estimulador na construção de uma práxis, em que “[...] o sujeito faz a experiência na qual está inserto e a experiência o faz" (ONOCKO-CAMPOS, 2012, p. 112).

\section{Considerações finais}

A pesquisa, na modalidade de intervenção, pode enfatizar a importância de um processo de EPS realizado no serviço e envolvendo a equipe multiprofissional. É importante destacar que o uso do DSC, fundamentado nos pressupostos da pesquisa qualitativa, permitiu ampliar o foco na análise da representação da estratégia de EPS e mostrar seu significado aos envolvidos.

Verificamos, por meio dos dois grupos focais, realizados de forma prévia e posterior à intervenção, diversas mudanças que aconteceram com relação à operacionalização da EPS, seu alcance e efetividade como ferramenta de gestão e de construção de uma práxis.

A mais significativa foi a avaliação comum de todos os envolvidos no sentido de serem incluídos na responsabilidade e se sentirem, realmente, partícipes da cogestão do processo e da finalização do produto. No movimento da EPS propõe-se que eles, ao se constituírem como sujeitos, tornem-se coparticipantes na tomada de decisão. 
Este trabalho pode ser um motivador para a realização de EPS em outros espaços institucionais, bem como em outros serviços locais, regionais ou nacionais, por representar de forma sistematizada e contínua a organização da proposta que incluiu, desde a composição grupal, o delineamento do processo e o produto das ações, constituindo a grupalidade e a riqueza por meio da heterogeneidade dos participantes.

Com relação às limitações do estudo, não foi possível incluir a perspectiva dos pacientes na análise, por necessitar de mais tempo para verificar as repercussões efetivas de mudança da equipe a partir da EPS.

Também não se verificou a real incorporação da EPS no serviço em função do tempo do estudo, embora se acredite que foram práticas assumidas pela equipe evidenciadas por sua apropriação e responsabilização, além de se garantir a frequência e realização das atividades por parte da gestão institucional naquele momento. Essa situação nos fez refletir o quanto o envolvimento da gestão torna-se importante e potente na implementação e continuidade dos processos de mudanças, considerando a reflexão e crítica sobre o trabalho realizado. Quando não se tem apoio institucional, os problemas podem ser processados por meio da prática reflexiva, porém, ao não se ter vazão para a discussão em âmbito institucional, isso pode implicar no desestímulo dos trabalhadores frente ao esforço e o empenho em se buscar novos caminhos para as práticas em saúde.

Dessa forma, este estudo pode contribuir para a formação de profissionais de saúde, ao sinalizar a importância da reflexão frente a processos educativos e formativos ampliando seus conhecimentos e crítica quanto às políticas públicas, para que possam inserir, exercer e se empoderar para sua efetiva realização no cotidiano de trabalho.

Como sugestão, novos estudos podem ser realizados em outros locais e instituições para que se possa acompanhar outras equipes que implementem processos de EPS e as construções a partir da mesma.

\section{Referências}

ARRUDA, M. P.; ARAÚJO, A. P.; LOCKS, G. A.; PAGLIOSA, F. L. Educação permanente: uma estratégia metodológica para os professores da saúde. Rev Bras Educ Méd, Rio de Janeiro, v. 32, n. 4, p. 518-24. Dez. 2010. Disponível em: http://www.scielo.br/pdf/rbem/v32n4/v32n4a15.pdf. Acesso em: 22 nov. 2015.

AUSUBEL, D. P.; NOVAK, J. D.; HANESIAN, H. Psicologia educacional. Tradução para português de Eva Nick et al .1. ed. Rio de Janeiro: Interamericana, 1980.

BARTH, P. O. et al. Educação permanente em saúde: concepções e práticas de enfermeiros de unidades básicas de saúde. Rev. Eletrônica Enferm., Goiânia, v.16, n. 3, p.604-611, set. 2014. 
Disponível em: https://www.revistas.ufg.br/fen/article/view/22020/17542. Acesso em: 29 jan. 2019.

BATISTA, K. B. C.; GONÇALVES, O. S. J. Formação dos profissionais de saúde para o SUS: significado e cuidado. Saúde Soc., São Paulo, v. 20, n. 4, p. 884-899, dez. 2011. Disponível em: http://www.scielo.br/pdf/sausoc/v20n4/07.pdf. Acesso em: 26 jan. 2019.

CAMPOS, G. W. S.; CUNHA, G. T.; FIGUEIREDO, M. D. Práxis e formação Paideia: apoio e cogestão em saúde. 1. ed. São Paulo: Hucitec, 2013.

CECCIM, R. B.; FEUERWERKER, L. C. M. O quadrilátero da formação para a área da saúde: ensino, gestão, atenção e controle social. Physis, Rio de Janeiro, v. 14, n. 1, p. 41-65, jun. 2004.

DELUIZ, N. Projovem trabalhador: avanço ou continuidade nas políticas de qualificação profissional? Bol. Téc. Senac, Rio de Janeiro, v. 36, n. 2, p. 19-31, maio/ago. 2010. Disponível em: http://www.bts.senac.br/index.php/bts/article/view/232/215. Acesso: 29 jan. 2019.

FEUERWERKER, L. C. M. Micropolítica e saúde: produção do cuidado, gestão e formação. 1. ed. Porto Alegre: Rede Unida, 2014.

HOFFMANN, L. M. A.; KOIFMAN, L. O olhar supervisivo na perspectiva da ativação de processos de mudança. Physis, Rio de Janeiro, v. 23, n. 2, p. 573-587, jun. 2013.

LAMANTE, M. P. S. et al. Análise de um percurso de Educação Permanente em Saúde: do planejamento à construção da práxis. In: CONGRESSO IBERO AMERICANO EM INVESTIGAÇÃO QUALITATIVA, 7., 2018, Fortaleza. Atas... Aveiro: Ludomedia, 2018. p. 346-354. Disponível em:

https://proceedings.ciaiq.org/index.php/ciaiq2018/article/view/1658/1611. Acesso em: 16 jan. 2019.

LEFEVRE, A. M. C.; CRESTANA, M. F.; CORNETTA, V. K. A utilização da metododologia do discurso do sujeito coletivo na avaliação qualitativa dos cursos de especialização "Capacitação e Desenvolvimento de Recursos Humanos em Saúde-CADRHU”, São Paulo 2002. Saúde Soc., São Paulo, v. 12, n. 2, p. 68-75, dez. 2003.

LEFÈVRE, F.; LEFÈVRE, A. M. C. Discurso do Sujeito Coletivo: pesquisa qualitativa levada a sério. 1. ed. São Paulo: USP, 2003. Disponível em: http://www.fsp.usp.br/ flefevre/Discurso_o_que_e.htm. Acesso em: 10 dez. 2018.

LEMOS, C. L. S. Educação Permanente em Saúde no Brasil: educação ou gerenciamento permanente? Ciênc. Saúde Colet., Rio de Janeiro, v. 21, n.3, p. 913-922, mar. 2016.

LIMA, V.V.; PADILHA, R.Q. Reflexões e inovações na educação de profissionais de saúde. 1. ed. Rio de Janeiro: Atheneu, 2018.

LOPES, S. R. S. et al. Potencialidades da educação permanente para a transformação das práticas de saúde. Comum. Ciênc. Saúde, Brasília, v. 18, n. 2, p. 147-155, abr/jun. 2007.

MARQUES, G. P. Planejamento estratégico e inovação na Escola Nacional de Saúde Pública-ENSP. 2011. Dissertação (Mestrado Profissional em Gestão de C\&T em Saúde) Escola Nacional de Saúde Pública Sergio Arouca, Fundação Oswaldo Cruz, Rio de Janeiro, 2011. Disponível em: bvssp.icict.fiocruz.br/lildbi/docsonline/get.php?id=2660. Acesso em: 10 dez. 2018.

MATUS, C. Política, planejamento \& governo. 1. ed. Brasília: IPEA, 1993. 
MERHY, E. E. Um ensaio sobre o médio e suas valises tecnológicas: contribuições para compreender as resstruturações produtivas do setor saúde. Interface, Botucatu, v. 4, n. 6, p. 109-116, fev. 2000.

MERHY, E. E.; FRANCO, T. B. Por uma composição técnica do trabalho em saúde centrada no campo relacional e nas tecnologias leves: apontando mudanças para os modelos tecnoassistenciais. Saúde Debate, Londrina, v. 27, n. 65, p. 316-323, set/dez. 2003.

MITRE, S. M. et al. Metodologias ativas de ensino-aprendizagem na formação profissional em saúde: debates atuais. Ciênc. Saúde Colet., Rio de Janeiro, v. 13, n. 2, p. 2133-2144, dez. 2008. Disponível em: http://www.scielo.br/pdf/csc/v13s2/v13s2a18.pdf. Acesso em: 15 jan. 2019.

OLIVEIRA, I. C.; CUTOLO, L. R. A. Humanização como expressão de integralidade. Mundo Saúde, São Paulo, v. 36, n.3, p. 502-506. 2012.

ONOCKO-CAMPOS, R. T. Psicanálise e saúde coletiva: Interfaces. 1. ed. São Paulo: Hucitec, 2012.

ROSSETTI, L. T. et al. Permanent education and health management: a conception of nurses. Rev. Pesqui. Cuid. Fundam., Rio de Janeiro, v.11, n.1, p.129-134, jan./mar. 2019. Disponível em: http://www.seer.unirio.br/index.php/cuidadofundamental/article/view/6513/pdf. Acesso em: 28 jan. 2019.

SANTOS FILHO, S. B.; BARROS, M. E. B.; GOMES, R. S. A Política Nacional de Humanização como política que se faz no processo de trabalho em saúde. Interface, Botucatu, v. 13, n. 1, p. 603-13, 2009.

STROSCHEIN, K.A.; ZOCCHE, D.A. Educação permanente nos serviços de saúde: um estudo sobre as experiências realizadas no Brasil.Trab. Educ. Saúde, Rio de Janeiro, v.9, n.3, p. 505519, nov. 2011. Disponível em: http://www.scielo.br/pdf/tes/v9n3/v9n3a09.pdf. Acesso em: 25 jan. 2019.

TORRES, O. M. A proposição metodológica dos estágios de vivência no Sistema Único de Saúde: um resgate histórico. In: FERLA, A. A. et al. (org.). VER-SUS Brasil: cadernos de textos. 1. ed. Porto Alegre: Rede Unida, 2013. p. 6-28. Disponível em:

http://www.otics.org/estacoes-de-observacao/versus/acervo/caderno-de-textos-do-ver-susbrasil/caderno-de-textos-do-ver-sus-brasil-documento-eletronico. Acesso em: 15 jan. 2019.

TRAD, L. A. B. Grupos focais: conceitos, procedimentos e reflexões baseadas em experiências com o uso da técnica em pesquisas de saúde. Physis, Rio de Janeiro, v. 19, n. 3, p. 777-796, 2009.

VASCONCELOS, M. F. F. et al. In-between policies (CEH - Continuing Education in Health and NHP - Humanization National Policy): towards a way to educate in/for the Brazilian National Health System (SUS). Interface, Botucatu, v. 20, n. 59, p. 981-991, 2016.

VYGOTSKY, L. S. A formação social da mente: o desenvolvimento dos processos psicológicos superiores. 6. ed. São Paulo: Martins Fontes, 1998.

Recebido em: 28 de fevereiro de 2019.

Aceito em: 15 de julho de 2019. 